\title{
Mammalian Gut Immunity
}

\author{
Benoit Chassaing ${ }^{1}$, Manish Kumar², Mark T. Baker ${ }^{3}$, Vishal Singh², Matam Vijay-Kumar²,4
}

The mammalian intestinal tract is the largest immune organ in the body and comprises cells from non-hemopoietic (epithelia, Paneth cells, goblet cells) and hemopoietic (macrophages, dendritic cells, T-cells) origin, and is also a dwelling for trillions of microbes collectively known as the microbiota. The homeostasis of this large microbial biomass is prerequisite to maintain host health by maximizing beneficial symbiotic relationships and minimizing the risks of living in such close proximity. Both microbiota and host immune system communicate with each other to mutually maintain homeostasis in what could be called a "love-hate relationship." Further, the host innate and adaptive immune arms of the immune system cooperate and compensate each other to maintain the equilibrium of a highly complex gut ecosystem in a stable and stringent fashion. Any imbalance due to innate or adaptive immune deficiency or aberrant immune response may

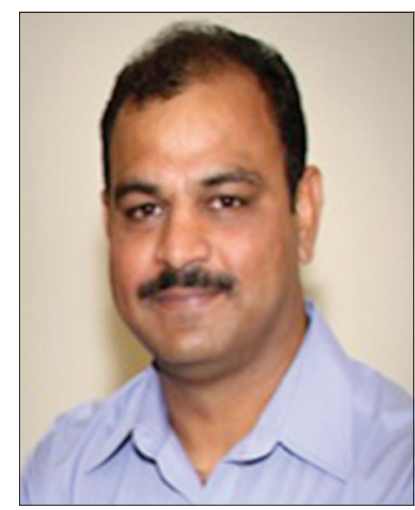

Dr. Matam Vijay-Kumar lead to dysbiosis and low-grade to robust gut inflammation, finally resulting in metabolic diseases. (Biomed J 2014;37:246-258)

\section{Key words: innate immunity, microbiota, NOD-like receptors, pattern recognition receptors, toll-like receptors}

$\mathrm{M}$ ammalian intestines harbor a large number of bacteria, specifically in the distal intestine, collectively known as the microbiota. In the last decade, an upsurge of studies describing the importance of the gut microbiota in host health and disease has convincingly demonstrated that colonization by diverse and stabilized microbiota is absolutely essential for the proper development of both innate and adaptive arms of the immune system.

A great deal of recent research indicates that the metabolic functions of the microbiota are substantial and comparable in magnitude to those of the liver. The microbiota can, for example, influence the fatty acid composition of the retina and lens of the eye, affect the bone density, and help vascularization of the gut. ${ }^{[1]}$ This bioreactor provides essential nutrients like biotin and vitamin $\mathrm{K}$ and digests complex dietary fiber, generating butyric acid, a major source of fuel for the gut epithelia. ${ }^{[2]}$ Eons of coevolution, driven by a common interest, have made the microbiota an immune system partner in the battle against bacterial pathogens. Specifically, the microbiota functions as an entrenched competitor for food, space, and anchorage sites, thus competitively excluding the invading enteropathogens (colonization resistance). Conversely, two recent studies indicate that the microbiota facilitates successful transmission of pathogenic viruses, ${ }^{[3,4]}$ and multiple murine models of inflammatory disease, from colitis to arthritis, require a gut microbiota. Further, that the composition of the microbiota is a determinant of disease severity indicates that the microbiota can also constitute a major threat to its host.

Maintaining the homeostasis of such a complex ecosystem has necessitated the development of a specialized "mucosal immune system" (MIS) that expediently detects and clears transient pathogens while also keeping beneficial opportunists on the correct side of the gut epithelial monolayer. In other words, there is a continuous crosstalk between epithelia and the microbiota in such a way that epithelia are well prepared to respond to any invasion by virtue of their ability to secrete a plethora of immune cell

From the ${ }^{1}$ Center for Inflammation, Immunity and Infection, Instittute for Biomedical Sciences, Georgia State University, Atlanta, GA, USA; ${ }^{2}$ Department of Nutritional Sciences, The Pennsylvania State University, University Park, PA, USA; ${ }^{3}$ Department of Biology, Georgia State University, Atlanta, GA, USA; ${ }^{4}$ Department of Medicine, The Pennsylvania State University College of Medicine, Hershey, PA, USA Received: Jan. 02, 2014; Accepted: Apr. 09, 2014

Correspondence to: Dr. Matam Vijay-Kumar, Department of Nutritional Sciences, The Pennsylvania State University, PA, USA. 323 Chandlee Laboratory, University Park, PA 16802, USA. Tel: 814-8652786; Fax: 814-8636103; E-mail: mvk13@ psu.edu

DOI: $10.4103 / 2319-4170.130922$ 
chemoattractants (analogous to "To make peace, prepare for war"). As this must be done while minimizing harm to beneficial microbes and host tissues, the MIS has developed an intricate system of communication with the microbiota, largely mediated by toll-like receptor (TLR) and nucleotide oligomerization domain-like receptor (NLR) pattern recognition receptors (PRRs). It appears that both the innate and adaptive immune systems have evolved to require microbial interactions for their proper development, ${ }^{[5-7]}$ as schematically represented in Figure 1. Supporting this notion, germ-free mice have reduced gut secretory immunoglobulin A ( $\operatorname{IgA}$ ), defects in development of gut-associated lymphoid tissues, and smaller Peyer's patches and mesenteric lymph nodes. ${ }^{[8]}$ In this review, we describe the recent advances in the mammalian MIS, focusing on the interplay between innate and adaptive immune cells and their effector molecules in the homeostasis of the microbiota, maintenance of tolerance, and mounting an appropriate inflammatory/immune response against an insult/invading pathogen.

\section{Physical and chemical barriers in the gut}

The mammalian gut is the primary site of interaction between the host immune system and the luminal contents, including not only food-derived antigens and toxins but also the microbiota. ${ }^{[9]}$ Mucosal immunity begins in the epithelium when microbes encounter the host at mucosal epithelial surfaces while attempting to colonize and establish themselves. The majority of these microbes and their metabolites are excluded from internal access to the host by both physical and chemical barriers. The physical barriers include a single layer of epithelial cells, their intercellular tight junctions, and the mucus that covers the epithelial surface. ${ }^{[9]}$ Further, the physical barrier is well supported by a delicate balance of chemical barriers such as acidity (low pH), detergents (bile salts), proteolytic enzymes (trypsin), cell wall degrading enzymes (lysozyme), and antibacterial proteins (defensins, etc.) that keep the microbial population in check. In addition, the unidirectional peristaltic movements of the intestine also aid in preventing entry of microbes from the dense distal gut contents to the small intestine.

\section{Mucus layer: Lubricating and trapping barrier}

The mucus layer covering epithelial surfaces lubricates the intestinal tract. It displays a sticky gel-forming ability due to its rigid protein structure and high cohesion. Mucus can be regarded as the first line of intestinal physical defense against microbial pathogens, helping in trapping the perturbing microbe. ${ }^{[10,11]}$ Mucins, the major components of the

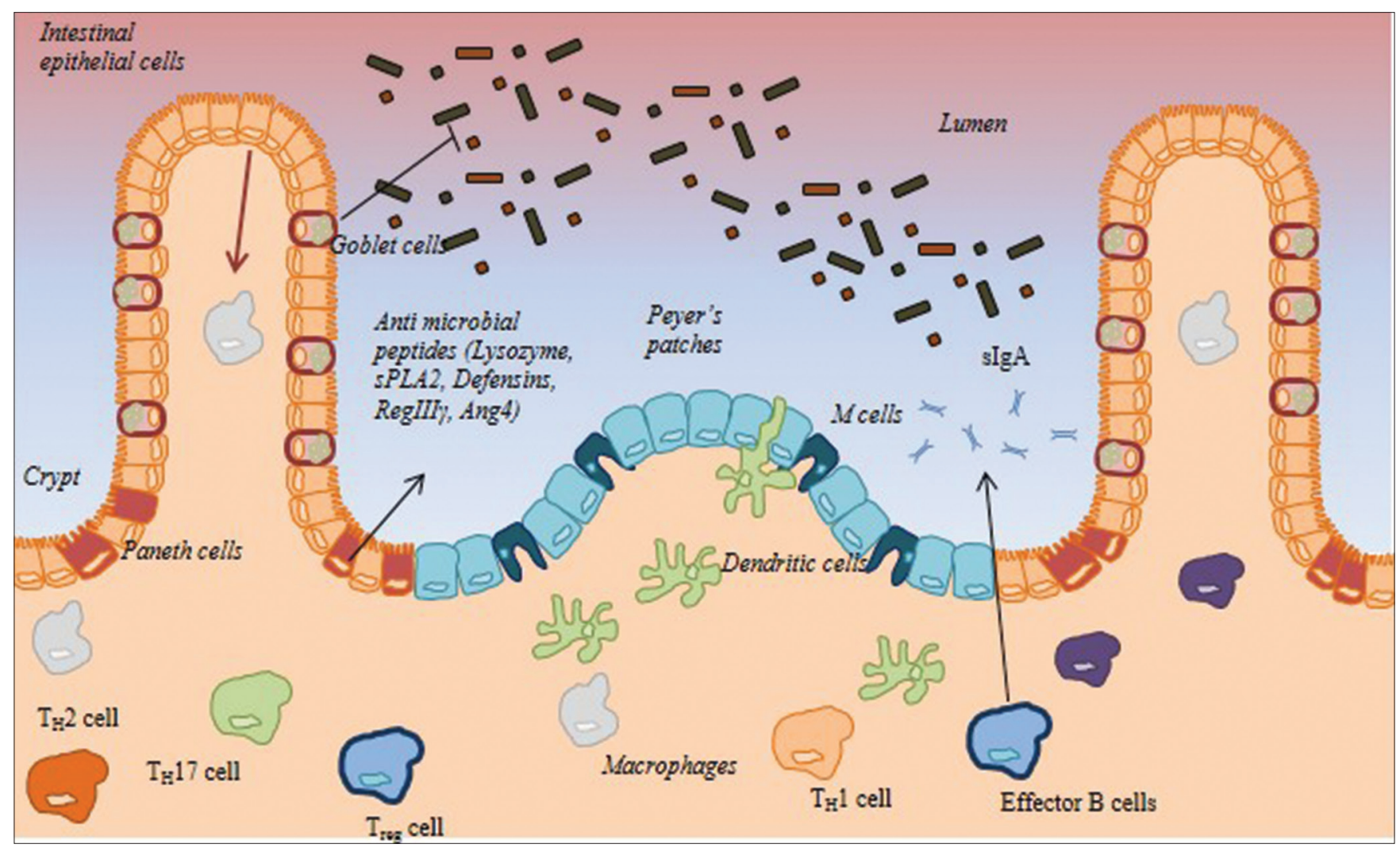

Figure 1: Mucosal immune system in the gut. In the normal state, PRR-microbiota interactions result in the secretion of antimicrobial peptides and the development of gut-associated lymphoid tissue (GALT). Crosstalk between microbiota and intestinal immune system elicit homeostatic factors such as IgA and defensins that maintain microbiota homeostasis and epithelial barrier integrity. 
mucus layer, are secreted by goblet cells that are interspersed among enterocytes throughout the epithelium. Mucins are high molecular weight (MW) glycoproteins with extensive glycosylation and sugar moieties attached to serine or threonine residues by $O$-glycosidic bonds. Changes in mucin composition might underlie the etiology of some diseases like ulcerative colitis and Helicobacter pylori gastritis. ${ }^{[12]}$

It is now well established that mucins have also a more direct role in combating pathogens and parasites, playing an important part in the coordinated immune response to infection. ${ }^{[13,14]}$ They also serve as an attachment site for microorganisms by interaction between many bacterial components. However, overexpression of some mucin proteins leads to cancer, ${ }^{[15]}$ while deficiency leads to gut inflammation and colitis (MUC-2). ${ }^{[16]}$ Recently, goblet cells have also been implicated in providing oral tolerance. ${ }^{[17]}$ This study shows that in the steady state, small intestine goblet cells function as passages delivering low-MW soluble antigens from the intestinal lumen to underlying immune cells [CD103 + lamina propria dendritic cells (DCs)]. This preferential delivery of antigens to DCs with tolerogenic properties implies a key role for goblet cells in gut homeostasis. ${ }^{[17]}$ Recently, it has been shown that mice deficient in colonic epithelial specific fatty acid synthase (FAS), unable to acylate MUC-2 with palmitic acid ( $S$-palmitoylation) leading to defective secretion and function, exhibit disruptions in the intestinal mucus barrier as well as increased intestinal permeability, colitis, systemic inflammation, and changes in gut microbial ecology. ${ }^{[18]}$

\section{Epithelial barrier: Gate keeper function}

The gastrointestinal epithelium forms a critical interface between the internal host and the luminal contents. A majority of the epithelia are absorptive cells (enterocytes) and must also support paracellular and transcellular transport of nutrients, electrolytes, and water. Enterocytes are one of the most rapidly regenerating cells in the body, matched by a high rate of apoptosis allowing for maintenance of epithelial cell homeostasis and permitting the epithelium to heal rapidly following injury. ${ }^{[19,20]}$ The barrier formed by epithelia must, therefore, be highly regulated and selectively permeable. The stability and function of the epithelial barrier depends on a complex of proteins composed of different intercellular junctions, which include tight junctions (zona occludens and claudins), adherens junctions (E-cadherin and $\beta$-catenin), and desmosomes. ${ }^{[21]}$ Accordingly, the permeability to various nutrients varies at individual sites and exhibits regional differences in the specific nutrients and ions transported. Epithelia are also equipped with numerous pumps, which help in maintaining unidirectional/vectorial secretion molecules. Interestingly, mice deficient in the multi-drug resistance 1 (MDR1) pump, involved in pumping several biological molecules, develop spontaneous gut inflammation similar to human inflammatory bowel disease (IBD) that could be prevented by antibiotic treatment. ${ }^{[22,23]}$

\section{Direct innate immune activity of gut epithelia}

Beyond serving as a physical barrier to microbes and luminal contents, the epithelium is also known to secrete a variety of molecules, which help in maintaining intestinal homeostasis. In other words, intestinal epithelia can be viewed as "accessory cells" of the MIS. Epithelia secrete an extensive panel of cytokines and chemokines that regulate chemotaxis of immune cells such as neutrophils, macrophages, basophils, and T-cells. ${ }^{[24]}$ The list of epithelial specific effector molecules is growing considerably due to the development of microarray and other sensitive analytical techniques, including germ-free and Cre-recombinase technology, as well as bone marrow chimeras. Cytokine secretion by intestinal epithelial cells (IECs) has been observed in a variety of cell lines, with significant overlap in cytokines secreted by immune cells. Even if their cytokine secretion is less than that of immune cells (e.g. macrophages), the fact that IECs are the most abundant cells at the mucosal surfaces suggests that their level of secretion has an important effect on the local cytokine concentrations. However, the relative contribution of IEC cytokines has not been clearly discerned.

IECs secrete a number of chemotactic cytokines (chemokines) that direct the chemotaxis and thus control the mucosal populations of both innate and adaptive immune cells. Epithelial-derived chemokine interleukin-8 (IL-8, CXCL8; mouse equivalent keratinocyte-derived chemokine, $\mathrm{KC})^{[25]}$ and epithelial neutrophil chemoattractants, including epithelial neutrophil attractant-78 (ENA-78, CXCL5), ${ }^{[26]}$ Gro-a (CXCL1), and Gro-b (CXCL2), ${ }^{[27]}$ regulate neutrophil chemotaxis. For instance, secretion of ENA-78 is considerably delayed but longer lasting than that of IL-8, suggesting a distinct role of these chemokines in responding to pathogens or inflammatory stimuli. Epitheliasecreted chemokines, including monocyte chemotactic protein (MCP-1; CCL2), macrophage inflammatory protein (MIP1 $\alpha$; CCL3) and RANTES/CC L5 (regulated upon activation, and presumably secreted), primarily regulate the monocyte recruitment. MIP1 $\alpha$ appears to play a major role in the recruitment of mucosal DCs. ${ }^{[27]}$

The IEC also secretes chemokines that drive recruitment of various T-cell subpopulations in the mucosa. These chemokines are critical for directing the recruitment of intraepithelial lymphocytes (IELs) and include interferon inducible protein (IP-10), monokine induced by interferon (IFN)- $\gamma$ (Mig), and IFN-inducible T-cell $\alpha$-chemoattractant (I-TAC) ${ }^{[28]}$ Unlike neutrophils, mucosal IELs are normally present in the mucosa, consistent with the observation that T-cell chemoattractants are constitutively expressed. ${ }^{[29]}$ 
Beyond orchestrating the recruitment of a variety of immune cells, the IECs also secrete a number of proinflammatory cytokines, with tumor necrosis factor (TNF)- $\alpha$ and IL- 6 being the best examples. ${ }^{[30,31]}$ The secretion of these cytokines affects the local inflammatory state, and also exhibits a substantial effect over systemic cytokine levels. For instance, TNF- $\alpha$ is not only a potent amplifier of other proinflammatory cytokines and chemokines, but also primes IECs to produce proinflammatory enzymes inducible nitric oxide synthase (iNOS) and cyclooxygenase-2 (COX-2), and activates neutrophils to generate more reactive oxygen species (ROS) and degranulation when encountering pathogenic stimuli. These IECs' innate immune activity, in cooperation with professional immune cells, can have substantial influence on both microbiota and host tissue homeostasis.

In addition to the soluble immunomodulators, the IECs also regulate a variety of adhesion molecules that influence the interaction of epithelium with infiltrating immune cells. IEC expression of neutrophil ligands is thought to play a major role in regulating adherence and transepithelial migration (diapedesis) of neutrophils. Specifically, key roles of epithelial CD47 and signal regulatory protein (SIRP) 1a in regulating neutrophil transmigration have been demonstrated. ${ }^{[32,33]}$ Intracellular adhesion molecule 1 (ICAM-1) is markedly upregulated in inflammatory conditions and possibly plays a role in increased neutrophil-epithelial adherence associated with IBD. ${ }^{[34]}$

IECs are also known to secrete soluble receptors which can neutralize the bioactivity of proinflammatory cytokines. For instance, inflammasome activation results in the secretion of potent proinflammatory cytokines IL- $1 \beta$ and IL-18. The biologic activity of inflammasome cytokines is finely regulated by the expression of endogenous, constitutively expressed soluble inhibitor proteins. Indeed, the absence of these anti-cytokines results in uncontrolled inflammation that causes tissue damage to the host. ${ }^{[35]} \mathrm{A}$ well-studied example of regulation of inflammasome cytokines is the secretory IL-1 receptor antagonist (sIL-1Ra), which competes with IL-1 $\beta$ for its receptor, thus dampening the bioactivity of this potent proinflammatory cytokine. IEC sIL-1Ra expression can be induced by proinflammatory stimuli, such as IL-1 $\beta$ itself and lipopolysaccharide (LPS), as well as by a variety of immunomodulators such as granulocyte-macrophage colony-stimulating factor (GM-CSF), IFN- $\beta$, IFN- $\gamma$, and flagellin. ${ }^{[36-38]}$ Importantly, sIL-1Ra is much more broadly expressed than IL-1 $\beta$, allowing cells that do not make IL-1 $\beta$ to have a role in regulating its activity. Similarly, epithelia can induce IL-18 binding protein (IL-18BP) in response to the proinflammatory cytokine IFN- $\gamma$, which is a potent inhibitor of IL-18. ${ }^{[38]}$

A key aspect of the epithelium's role in the MIS is its ability to finely regulate immune cell function and activation. Therefore, activation and return to the normal state should be tightly linked. For instance, the inability to recruit immune cells rapidly in response to pathogens would make the host more susceptible to systemic infection (e.g. MyD88-deficient mice, discussed below). Conversely, excessive and uncontrolled recruitment, especially of neutrophils, is likely to be detrimental because it can lead to substantial damage of host tissue, as observed in chronic IBD. Thus, IECs exert tight control over their immune-modulating genes of the MIS, especially those associated with immune cell recruitment, such as the neutrophil chemoattractant IL-8.

\section{Microfold cells}

Another structurally distinct epithelial cell type is the microfold $(\mathrm{M})$ cells, characterized by a microfolding plasma membrane. These cells are immunologic sentinels playing an important role in mucosal adaptive immunity. ${ }^{[39]}$ They are considered as specialized epithelia and are present over the surface of the B-cell follicles [Peyer's patches and isolated lymphoid follicles (ILFs)]. They are the principle cells responsible for sampling intestinal microbiota and pathogens. ${ }^{[40]}$ Structurally, M-cells have shorter/scanty microvilli and much less glycocalyx on their surface, unlike other enterocytes, which help them to pick up particles from the lumen and funnel them to the lymphoid tissues on their basolateral sides. Owing to this nature, these cells have emerged as a center point in the development of oral vaccines. ${ }^{[4]}$ However, they are also among the most exploited cell types in the lumen by several pathogens (e.g. Salmonella typhimurium, Yersinia spp, adherent-invasive Escherichia coli, reoviruses) to facilitate their invasion. ${ }^{[42-44]}$ Recently, "villous" M cells have been reported, which are present on the villous epithelium of the small intestine and share functional and structural characteristics of normal $\mathrm{M}$ cell but lack any lymphoid association. ${ }^{[4]}$

\section{Paneth cells}

Another important component of the MIS is "Paneth cells," named after Josef Paneth. These columnar cells have prominent granules and reside at the base of the crypts of Lieberkühn in the small intestine. Each crypt contains approximately 15 stem cells and 10 Paneth cells. Occasionally, Paneth cells are also present in the stomach and colon as a metaplastic response to gut inflammation. Unlike IECs, which have a life span of 3-5 days, Paneth cells live relatively longer ( $>30$ days). These cells have large apical defensin-rich secretory granules, which are released into narrow epithelial crypts via exocytosis (i.e. merocrine secretion) in response to various stimuli that include bacterial products but not those of fungi or protozoa. Human Paneth cells express two alpha-defensins: Human defensin 5 (HD5) and human defensin 6 (HD6). ${ }^{[46]}$ They also secrete lysozyme, secretory phospholipase $\mathrm{A} 2$, and regenerating islet-derived protein 
III-alpha (RegIIIA) ${ }^{[47]}$ However, unlike humans, mice and rats express more than two alpha-defensins. Mouse Paneth cells also secrete numerous cryptdin-related peptides and an RNase, angiogenin 4 (for further details see Ref. [47]). Defensins are synthesized as prepropeptides, which are eventually processed by Paneth cell trypsin in humans and matrix metalloproteinase-7 (MMP-7) in mice. ${ }^{[48]}$ Data from experimental animals indicate that defensins make up around $15 \%$ of the total antimicrobial activity of the gut in both germ-free and conventional mice ${ }^{[49]}$ and the concentration of defensins in crypts can reach $>10 \mathrm{mg} / \mathrm{ml}$. ${ }^{[50]}$

\section{Intestinal macrophages}

Macrophages (MФ) are one of the most abundant leukocytes in the subepithelial lamina propria of mammals, and this population likely makes up the largest macrophage reservoir in the body. The number of $M \Phi$ in different locations of the intestine seems to be closely associated with the relative microbioal load, and they are thus highest in the large intestine and least in the intestines of germ-free mice. Given that IBD is believed to be driven by aberrant immune response to commensal microbiota, which are present in large quantities in the normal colon, and that $\mathrm{M} \Phi$ are constantly present there, it is intriguing to consider why the intestine is not in a permanent state of inflammation. ${ }^{[51]} \mathrm{It}$ has been shown in numerous studies that unlike MФ from other tissues, mucosal MФ do not respond to TLR ligands by secreting proinflammatory cytokines or chemokines such as IL-12, IL-23, TNF- $\alpha$, IL-1, IL-6, or CXCL10 (IP-10) nor do they up-regulate co-stimulatory molecules or generate ROS and nitric oxide (NO) production under these conditions ${ }^{[51]}$ They do, however, synthesize IL-10 (a major anti-inflammatory cytokine) constitutively or in response to TLR ligands. ${ }^{[5,53]}$ Further, resident gut M $\Phi$ are highly phagocytic and express CD36, a receptor that facilitates phagocytosis of apoptotic cells. ${ }^{[1]}$ They also exhibit strong bactericidal activity without initiating overt inflammation, allowing local $\mathrm{M} \Phi$ to act as a firewall against any commensal bacteria that breach the epithelial barrier. They do not express high levels of co-stimulatory molecules such as CD80, CD86, or CD40, but they do express cytosolic PRRs, which are critical for their antibacterial activity. ${ }^{[54]}$ In addition, the resident intestinal $M \Phi$ do not only contribute to gut homeostasis by acting as a waste disposal unit for local bacteria and dead cells, but also actively regulate epithelial integrity. As a result, depletion of resident $М \Phi$ increases susceptibility of mice to experimentally induced colitis. ${ }^{[55,56]}$ Expression of the transcription factor peroxisome proliferator-activated receptor- $\gamma$ (PPAR- $\gamma$ ) by mucosal M $\Phi$ is an alternate mechanism by which they can prevent local inflammation, via its ability to suppress proinflammatory gene expression. ${ }^{[57]}$ Thus, M $\Phi$ in the MIS can be viewed as a functional subset involved in the normal physiologi- cal processes of tissue remodeling and avoiding immune response to commensal microbes.

The accumulated data indicate that most of the immune cells in the MIS are capable of constitutive IL-10 secretion. It is worth mentioning that deletion of IL-10 results in the development of spontaneous colitis. ${ }^{[58]}$ In addition, inhibition of IL-10 signaling in myeloid cells via targeted deletion of signal transducer and activator of transcription 3 (STAT3) results in spontaneous colitis. ${ }^{[59]}$ Clearly, IL-10 is a critical physiologic mediator of intestinal $\mathrm{M} \Phi$ inertia. An important issue that is not yet resolved is whether the altered $M \Phi$ behavior that occurs during inflammation reflects changes in the normally inert resident $\mathrm{M} \Phi$ or is a result of infiltration of new, highly responsive professional $М \Phi$. The existing evidence favors the latter idea, but it is not clear if these newly arrived $M \Phi$ belong to a distinct lineage from resident $M \Phi$. Several lines of evidence indicate that inflammatory M $\Phi$ are derived from a newly recruited population that originated from circulating Ly6 $\mathrm{C}^{\mathrm{hi}}$ monocytes.

\section{Intestinal T lymphocytes}

T-cells are one of the most abundant leukocytes in the subepithelial lamina, and are important players in mammalian gut immunity as highlighted by the dramatic consequences of their absence, such as human immunodeficiency virus (HIV) infection. Germ-free mouse lamina propria is devoid of T-cells, with only primary follicles in Peyer's patches ${ }^{[60,61]}$ Following colonization with bacteria, the mucosal T-cell population rapidly increases to a normal level as seen in conventional mice, demonstrating that microbial antigens or products are necessary for maintaining the T-cell population. In general, the T-cell population in healthy animals is principally composed of type $1 \mathrm{~T}$ helper (TH1) and type $2 \mathrm{~T}$ helper (TH2) cells. While Crohn's disease is associated with a TH1 cytokine profile, ulcerative colitis is TH2 biased. ${ }^{[62]}$ This concept has been further complicated by the description of tolerizing regulatory T-cells (Tregs) and by proinflammatory TH17 cells, a novel T-cell population characterized by the master transcription factor RAR-related orphan receptor gamma (ROP $\gamma \mathrm{t}$ ), and the surface markers IL23R and C-C chemokine receptor type 6 (CCR6). ${ }^{[62]}$ TH17 cells differentiate under the influence of IL1 $\beta$, IL6, IL21, IL23, and transforming growth factor beta (TGF) $-\beta .^{[63-65]} \mathrm{TH} 17$ cells are known to secrete proinflammatory cytokines IL17A, IL17F, IL21, IL22, and IL26, and the chemokine CCL20, and several studies demonstrated an important role of TH17 cells in intestinal inflammation, particularly in Crohn's disease. ${ }^{[62]} \mathrm{TH} 17$ cells play a central role in the neutralization of pathogens and commensal microbiota, both by coordinating neutrophil influx and by maintenance or restitution of epithelial barrier integrity via IL17 and IL22 synthesis. Interestingly, mucosal epithelia express 
receptors for these TH17 cytokines, promoting tight junction formation, antimicrobial peptide production, as well as mucus production.

\section{Intestinal DCs}

DCs are the most potent professional antigen-presenting cells (APCs). Unlike macrophages, DCs can initiate the primary immune response by activating naïve T-cells and regulate proinflammatory or tolerogenic immune responses. ${ }^{[66]}$ In addition, DCs also express PRRs for sensing microbial products depending on the environment. DCs are very flexible and able to polarize $\mathrm{TH} 1, \mathrm{TH} 2$, or Treg immune responses depending on their prior exposure to cytokines/microbial ligands. Once the DCs migrate to the sub-mucosa, they become highly efficient in sampling intestinal contents via dendrites for antigen capturing and processing ${ }^{[66]}$ occurring through the epithelial monolayer or M cells. ${ }^{[67,68]}$ Under physiological conditions, DCs have a regulatory role and prevent immune responses against food antigens and gut microbiota. ${ }^{[66]}$ They attain a regulatory profile by various signals [thymic stromal lymphopoietin (TSLP), IL-10, TGF- $\beta$ ], more specifically by retinoic acid (RA), an active form of vitamin A. In the presence of $\mathrm{RA}$, intestinal DCs (but not DCs in other tissues) acquire the ability to generate Tregs and IgA-secreting B-cells using enzymes that convert vitamin A into RA. ${ }^{[69]}$ Intestinal DCs can be distinguished from other tissue DCs by (i) decreased expression of PRRs, (ii) reduced expression of co-stimulatory molecules, and thus, reduced antigen presentation, (iii) higher production of anti-inflammatory cytokines (IL-10), (iv) favoring differentiation of antigen-specific Tregs and IgA secretory B-cells, and (v) inducing immune tolerance via the expression of gut-homing markers both in Tregs and IgA-secreting B-cells. Any changes in the above characteristic features of intestinal DCs result in an aberrant immune response toward the microbiota, possibly leading to IBD.

\section{Innate lymphoid cells}

Innate lymphoid cells (ILCs) are the more recently discovered innate immune cells in the MIS ${ }^{[70,71]}$ that are defined by the lack of specific antigen receptors and play a central role in the regulation of gut epithelial cell barrier integrity, and of immunity, inflammation, and tissue repair in the intestine. ${ }^{[72]}$ ILC depletion using a mouse model of non-obese diabetic-recombination activating gene-1 (NOD-Rag1 null) IL-2 receptor common gamma chain double-deficient mice ${ }^{[71]}$ results in peripheral dissemination of commensal bacteria and systemic inflammation, which was rescued by administration of IL-22, suggesting that IL-22 produced by these cells plays a key role in maintaining barrier function. ${ }^{[73]}$

\section{Secretory IgA}

The most abundant adaptive immune factor in the intestinal lumen is $\operatorname{sg} \mathrm{A}$, which plays a major role in intestinal homeostasis. It is mainly secreted as a dimer and covalently associated with epithelial glycoprotein secretory component. Subepithelial B-cells in the intestine secrete IgA, which translocates via the epithelial monolayer and whose subsequent secretion into the intestinal lumen represents a major immunological barrier. ${ }^{[74]}$ The major functions of sIgA include (i) protection against enteropathogens (e.g. Salmonella, rotavirus), (ii) providing herd immunity against horizontal fecaloral spread of enteropathogens, and (iii) limiting the spread of intestinal-derived antigens into the circulation (see Ref. ${ }^{[75]}$ for details). The luminal sIgA plays a prominent role in protecting against Vibrio cholera and enterotoxigenic E. coli. Also, the host microbiota plays a key role in IgA secretion, as it has long been known that gnotobiotic mice display strikingly reduced levels of sIgA in their feces.

IECs, which are in close proximity with the microbiota, play a role in the process of IgA secretion. The best example is that the development of ILFs from cryptopatches is dependent on sensing of the microbiota by nucleotide-binding oligomerization domain protein 1 (NOD1), which results in the secretion of the B-cell chemoattractant CCL20 by IECs. ILFs are the predominant sites for $\mathrm{SIgA}$ production in a T-cell independent fashion. Inflammation of the intestine substantially increases sIgA secretion into the lumen. For instance, mice expressing a constitutively active form of TLR-4 lacked spontaneous colitis, but showed an increase in B-cell recruitment and trophic factor production, leading to an increase in the production of $\operatorname{sIgA} \cdot{ }^{[76]} \mathrm{In}$ addition to influencing B-cell recruitment, IECs have been shown to constitutively produce factors that directly stimulate IgA production via production of IL-6, and induce B-cell IgA ${ }_{2}$ class-switching via stimulating a proliferation-inducing ligand (APRIL). Innate immunity signaling via TLR also augments the transit of sIgA into the lumen, as exposure of IECs to LPS or heat-inactivated E. coli leads to increased expression of the polymeric Ig receptor, which binds to subepithelial IgA and shuttles it across epithelia. Even though several studies indicate that DCs that have sampled luminal antigens are a driving force behind the secretion of sIgA, microbe-exposed epithelia can also influence this process, further highlighting the importance of IECs in the MIS. Tregs also play a role in the induction of $\operatorname{sigA}$, and the induction of Tregs coincides with a powerful induction of $\operatorname{sIg} \mathrm{A}^{[77]}$ upon microbiota colonization. Both humans and mice that selectively lack IgA exhibit weak symptoms since IgM can compensate for IgA deficiency. ${ }^{[78,79]}$

\section{The microbiota helps to develop the host MIS}

The mammalian intestines are inhabited by a large, diverse community of microbes, which are collectively 
known as the gut microbiota; it contains approximately $10^{14}$ bacteria, weighing 1-2 kg, and comprises 6-10 major phyla and about 3000 species. ${ }^{[80]}$ The composition of the microbiota is thought to remain stable throughout the life of the host, even when there are drastic changes in the diet and level of physical activity, during pregnancy, and with the use of broad-spectrum antibiotics. ${ }^{[81,82]}$

Interestingly, "germ-free" (also referred to as gnotobiotic) mice, which lack a microbiota, have considerable immune and metabolic defects. ${ }^{[83]}$ However, accumulated data from a variety of immune-deficient murine models indicate that altered microbiota plays a central role in origination of intestinal inflammation and metabolic diseases. ${ }^{[84]}$ Together, these studies suggest that homeostasis of the microbiota is required to maintain a beneficial symbiotic relationship.

For this purpose, the MIS has developed multiple ways to maintain microbiota-host homeostasis and defend against pathogens. PRRs of the innate immune system, particularly the TLRs and NOD-like receptors (NLRs), play essential roles in these processes. Both TLRs and NLRs recognize a variety of broadly conserved microbial components.

\section{Pattern recognition in the gut}

Given the potentially overwhelming microbial biomass in the gut and the fact that several PRRs can sense their cognate agonists at picomolar levels, the host has evolved a number of effective mechanisms to prevent constant/ repeated PRR activation while maintaining the ability to activate PRRs when needed, so as to maximize the benefits conferred by microbiotal stability [Tables 1 and 2].

Apart from the physical obstacles to activation of PRRs by abundant luminal microbial ligands [Tables 1 and 2], namely the aforementioned thick mucus layer laden with antibacterial compounds, additional mechanisms exist to inhibit aberrant PRR activation in the gut. One such mechanism is for the intestine to be selective about the cell types and the conditions in which TLRs are expressed. For instance, TLRs 2 and 4, receptors for the bacterial cell wall components peptidoglycan and LPS, respectively, are barely expressed in healthy IECs but are upregulated in conditions associated with IBDs. ${ }^{[85]}$ In addition, activation of TLR-4, the most proinflammatory of the PRRs, in IECs is also avoided by limiting the availability of co-receptors, myeloid differentiation factor 2 (MD-2), CD14, and LPS-binding protein. ${ }^{[86]}$ TLRs 2 and 4 are also expressed at greater levels by IECs that have yet to migrate up the villus, ensuring that robust activation of these PRRs occurs only if the crypt, which is not normally colonized, is threatened. ${ }^{[87]}$ Furthermore, the receptor for flagellin, TLR-5, is expressed only on the basolateral side of IECs, a strategy that allows the host to generate a response only to invasive flagellated microbes ${ }^{[88]}$ TLR-9 is unique among the TLRs in that it is capable of dampening signaling through all TLRs. While basolateral activation of
TLR-9 by microbiotal DNA elicits a classical nuclear factor kappa-light-chain-enhancer of activated B cells (NF- $\mathrm{KB}$ ) mediated inflammatory response, apical TLR-9 attenuates such a response via an alternative signaling pathway that blunts IL-8 activity, inhibiting neutrophil chemotaxis. ${ }^{[89,90]}$ In addition, constant exposure to their respective ligands can result in immunological tolerance, a mechanism that may also protect against aberrant inflammation and even autoimmunity. ${ }^{[91]}$ Thus, the innate immune response in the gut may be viewed as preventing the excessive PRR activation that might result if the microbiota was not properly managed. Such tight control over microbiota/PRR interactions serves to limit aberrant inflammation.

In a similar fashion, nucleotide-binding and oligomerization domain (NOD)-like receptors (NLRs) have evolved in IECs to avoid overactive inflammatory responses toward the resident microbiota and also to preserve epithelial barrier integrity and functions by maintaining homeostasis. Recent studies targeting the intestinal microbiota in the context of NLR deficiencies suggest inherent alterations in bacterial density or abundance may underlie the development of inflammatory diseases. Inflammasomes have emerged as central regulators of intestinal infection, immunity, and inflammation. In addition to mediating intestinal epithelial integrity, antimicrobial responses, and initiating inflammation through generation of the cytokines IL- $1 \beta$ and IL- 18 , the inflammasome appears to play a pivotal role in the control of intestinal microbiota composition. ${ }^{[92]}$ Inflammasome-deficient mice show an aberrant microbial community, which is dominantly transmissible to healthy mice, leading to the transmission of non-alcoholic fatty liver disease (NAFLD), obesity, intestinal inflammation, and cancer. ${ }^{[33,94]}$

\section{Transcription factors in intestinal immunity}

The NF- $\kappa B$ signaling pathway in the gut epithelia is critical not only for the secretion of a myriad of chemoattractants but also for the induction of antimicrobials and proinflammatory enzymes, thus playing a key role in epithelial homeostasis. Accordingly, IEC-specific inhibition of $N F-\kappa B$ through conditional ablation of NF- $\kappa B$ essential modulator (NEMO) (IKB kinase-gamma, essential for $\mathrm{NF}-\kappa \mathrm{B}$ activation) induces spontaneous chronic intestinal inflammation in mice. ${ }^{[95]} \mathrm{NF}-\kappa \mathrm{B}$ deficiency led to apoptosis of colonic epithelial cells accompanied by impaired expression of antimicrobial peptides and translocation of bacteria into the mucosa. ${ }^{[95]}$ Concurrently, this epithelial defect triggered a chronic inflammatory response in the colon, initially dominated by innate immune cells but also involving $\mathrm{T}$ lymphocytes later. Importantly, deficiency of the gene encoding the adaptor protein MyD88 prevented the development of intestinal inflammation, demonstrating that TLR activation by intestinal bacteria is essential for disease pathogenesis. ${ }^{[95]}$ However, even if TLR activation by gut 
Table 1: Pattern recognition receptor ligands

\begin{tabular}{|c|c|c|}
\hline Receptor & Microbial product & References \\
\hline TLR-1 (with TLR-2) & $\begin{array}{l}\text { Mycobacterial lipoprotein } \\
\text { Triacylated lipoproteins }\end{array}$ & $\begin{array}{l}\text { Takeuchi, Sato et al., } 2002 \\
\text { Shimizu, Kida et al., } 2007\end{array}$ \\
\hline TLR-2 (with TLR-1 or TLR-6) & $\begin{array}{l}\text { Gram-positive bacteria } \\
\text { Peptidoglycan, lipoteichoic acid } \\
\text { Zymosan, liparabinomannan } \\
\text { Bacterial glycolipids, yeast mannan } \\
\text { GPI anchors of Trypanosoma cruzi } \\
\text { LPS from Leptospira interrogans } \\
\text { LPS from Porphyromonas gingivalis (more cylindrical) }\end{array}$ & $\begin{array}{l}\text { Aliprantis, Yang et al., 1999; Schwandner, Dziarski } \\
\text { et al., 1999; Takeuchi, Hoshino et al., 1999; Hajjar, } \\
\text { O'Mahony et al., 2001; Opitz, Schroder et al., 2001; } \\
\text { Werts, Tapping et al., 2001; Coelho, Klein et al., 2002; } \\
\text { Massari, Henneke et al., 2002 }\end{array}$ \\
\hline TLR-3 & $\begin{array}{l}\text { Viral dsRNA, synthetic polyinosinic acid: cytidylic acid } \\
\text { (poly I: C) }\end{array}$ & Alexopoulou, Holt et al., 2001 \\
\hline TLR-4 & $\begin{array}{l}\text { Gram-negative bacteria } \\
\text { LPS (conical shape), pneumolysin } \\
\text { Lipid A (strictly cylindrical, antagonist) } \\
\text { LPS from Rhodobacter sphaeroides (strictly cylindrical) } \\
\text { Flavolipin from Flavobacterium meningosepticum } \\
\text { Respiratory syncytial virus protein F } \\
\text { Aspergillus fumigatus hyphae } \\
\text { HSP } 60 \text { and 70, hyaluronan } \\
\text { Fibronectin A domain, fibrinogen } \\
\text { Necrotic cells, saturated fatty acids, taxol (only in mice) }\end{array}$ & $\begin{array}{l}\text { Poltorak, He et al., 1998; Kawasaki, Akashi et al., } \\
\text { 2000; Kurt-Jones, Popova et al., 2000; Ohashi, Burkart } \\
\text { et al., 2000; Byrd-Leifer, Block et al., 2001; Okamura, } \\
\text { Watari et al., 2001; Smiley, King et al., 2001; Bulut, } \\
\text { Faure et al., 2002; Johnson, Brunn et al., 2002; Rassa, } \\
\text { Meyers et al., 2002; Termeer, Benedix et al., 2002; } \\
\text { Vabulas, Ahmad-Nejad et al., 2002; Huang, Rutkowsky } \\
\text { et al., } 2012\end{array}$ \\
\hline TLR-5 & Flagellin & Hayashi, Smith et al., 2001 \\
\hline TLR-6 (with TLR-2) & $\begin{array}{l}\text { Mycoplasma lipoproteins, lipoteichoic acid, } \\
\text { peptidoglycan }\end{array}$ & $\begin{array}{l}\text { Schwandner, Dziarski et al., 1999; Morr, Takeuchi } \\
\text { et al., } 2002\end{array}$ \\
\hline TLR-7 and TLR-8 & Single-stranded RNA, imidazoquinalones & Diebold, Kaisho et al., 2004; Heil, Hemmi et al., 2004 \\
\hline TLR-9 & CpG DNA, hemozoin & Hemmi, Takeuchi et al., 2000 \\
\hline TLR-10 & Unknown & \\
\hline TLR-11 & $\begin{array}{l}\text { Uropathogenic bacteria } \\
\text { Profilin-like protein molecule in Toxoplasma gondii }\end{array}$ & $\begin{array}{l}\text { Zhang, Zhang et al., 2004; Koblansky, Jankovic } \\
\text { et al., } 2013\end{array}$ \\
\hline TLR-12 & Profilin-like protein molecule in Toxoplasma gondii & Koblansky, Jankovic et al., 2013 \\
\hline RIG-1 & $5^{\prime}$ triphosphorylated dsRNA & Yoneyama, Kikuchi et al., 2004 \\
\hline MDA-5 & Long dsRNA & Kato, Takeuchi et al., 2008 \\
\hline Protein kinase $\mathrm{R}$ & dsRNA & Williams 2001 \\
\hline Dectin-I & $\beta$-Glucans & Brown, Taylor et al., 2002 \\
\hline Mannose receptor & Liparabinomannan & Schlesinger, Hull et al., 1994 \\
\hline f-MLP receptor & f-MLP & Boulay, Tardif et al., 1990 \\
\hline Moesin & LPS & Amar, Oyaisu et al., 2001; Iontcheva, Amar et al., 2004 \\
\hline
\end{tabular}

Abbreviations: TLR: Toll-like receptor; RIG: Retinoic acid-inducible gene; MDA: Melanoma differentiation-associated protein; f-MLP: Formyl peptide; GPI: Glycosylphosphatidylinositol; LPS: Lipopolysaccharide; HSP: Heat shock protein; RNA: Ribonucleic acid; DNA: Deoxyribonucleic acid

bacteria is essential for disease pathogenesis, TLR signaling should be viewed more as a beneficial pathway that could also become harmful in an immunodeficiency situation, such as NEMO deletion. Furthermore, activation of TLRs by the microbiota is critical for protection against gut injury and associated mortality, revealing a protective function of TLRs on host-microbial interactions. ${ }^{[96,97]}$ In addition to NF- $\mathrm{KB}$, several other transcription factors such as T-bet and the STAT family also play a role in gut homeostasis. ${ }^{[98-101]}$

\section{Bacterial metabolites in the development of MIS}

Microbiota is known to play a key role in the development of proper gut-associated lymphoid system and gut homeostasis. However, the mechanism by which microbiota-derived signals and metabolites drive gut homeostasis was largely unknown. In a recent study, Smith et al. discovered that short chain fatty acids (SCFAs), such as acetate, butyrate, and propionate, generated via bacterial fermentation of dietary fiber play a key role in the expansion of intestinal but not extra-intestinal lymphoid tissue Tregs. ${ }^{[102]}$ SCFAs specifically increase the number of both in gnotobiotic and conventional mice. In addition, using co-culture experiments, SCFAs were found to improve the inhibitory activity of Tregs on CD4+. ${ }^{[102]} \mathrm{In}$ a T-cell adoptive transfer model of chronic colitis, mice pre-treated with propionate alone or SCFAs mix were substantially protected when compared to control mice. In a similar line, Arpaia et al. found that butyrate produced by microbiota facilitated 
Table 2: Nucleotide-binding and oligomerization domain-like receptors

\begin{tabular}{|c|c|c|c|}
\hline Family & Receptor & Ligands & References \\
\hline NLRA & CIITA & $? ?$ & \\
\hline NLRB & NAIPs & Flagellin, rod proteins & Kofoed and Vance 2011 \\
\hline \multirow[t]{4}{*}{ NLRC } & NOD-1 & $\begin{array}{l}\gamma \text {-d-Glu-DAP (iEDAP), meso-lanthionine, meso-DAP, } \\
\text { d-lactyl-1-ala- } \gamma \text {-Glu-meso-DAP-Gly (FK156), } \\
\text { heptanolyl- } \gamma \text {-Glu-meso-DAP-d-ala (FK565) }\end{array}$ & $\begin{array}{l}\text { Chamaillard, Hashimoto et al., 2003; Girardin, Travassos } \\
\text { et al., 2003; Wilmanski, Petnicki-Ocwieja et al., } 2008\end{array}$ \\
\hline & NOD-2 & $\begin{array}{l}\text { Muramyl dipeptide (MDP), } \\
\text { MurNAc-1-Ala- } \gamma \text {-d-Glu-1-Lys (M-TRILys) }\end{array}$ & Girardin, Boneca et al., 2003; Girardin, Travassos et al., 2003 \\
\hline & NLRC3/C5/X1 & $? ?$ & \\
\hline & NLRC4 & Flagellin, bacterial type 3 secretion system (T3SS) & Lightfield, Persson et al., 2008; Miao, Mao et al., 2010 \\
\hline \multirow[t]{7}{*}{ NLRP } & NLRP1 & Bacterial toxins, MDP, reduced level of cytosolic ATP (?) & $\begin{array}{l}\text { Boyden and Dietrich 2006; Faustin, Lartigue et al., 2007; } \\
\text { Frew, Joag et al., 2012; Levinsohn, Newman et al., 2012; } \\
\text { Liao and Mogridge 2013 }\end{array}$ \\
\hline & NLRP3 & $\begin{array}{l}\text { Toxins, bacterial and viral RNA, oxMito-DNA, ceramide, } \\
\text { cardiolipin, K+efflux, mitochondrial/lysosomal } \\
\text { disruption, ROS, crystals/aggregates, Ca++signaling, } \\
\text { Ex-ATP, silica crystals and aluminum salts }\end{array}$ & $\begin{array}{l}\text { Hornung, Bauernfeind et al., 2008; Tschopp and Schroder } \\
\text { 2010; Leemans, Cassel et al., } 2011\end{array}$ \\
\hline & NLRP6 & Bacterial products (?) & Anand, Malireddi et al., 2012; Anand and Kanneganti 2013 \\
\hline & NLRP7 & Bacterial acylated lipopeptides (acLP) & Khare, Dorfleutner et al., 2012 \\
\hline & NLRP10 & $? ?$ & \\
\hline & NLRP11 & $? ?$ & \\
\hline & NLRP12 & Acylated lipid A & Lupfer and Kanneganti 2013 \\
\hline NLRX & NLRX1 & Poly I: C & Hong, Yoon et al., 2012 \\
\hline
\end{tabular}

Abbreviations: NLR: Nucleotide-binding oligomerization domain-like receptor; CIITA: Class II, major histocompatibility complex, transactivator; NAIPs: Neuronal apoptosis inhibitory protein; NOD: Nucleotide-binding oligomerization domain; iEDAP: D-glutamyl-meso-diaminopimelic acid; RNA: Ribonucleic acid; DNA: Deoxyribonucleic acid; ATP: Adenosine triphosphate; ROS: Reactive oxygen species

extrathymic generation of Treg cells..$^{[103]}$ In addition, propionate potentiated de novo Treg generation in the periphery. These studies demonstrate that not only bacterial-associated ligands could participate in the proper development of host MIS, but also their metabolites can profoundly impact the generation of key regulatory cell populations of the adaptive immune system.

\section{Intestinal immunity to non-bacterial organisms}

The gut immune system is capable of mounting immune responses not only to bacteria, but also to a variety of protozoan parasites such as Toxoplasma, Entoamoeba, and Giardia, which are increasingly posing a major problem, especially in immunocompromised hosts. ${ }^{[104]}$ While susceptibility to chronic infection is propagated by TH1 cytokine responses (characterized by the production of IL-12, IL-18, and IFN- $\gamma$ ), immunity to intestinal-dwelling adult nematode worms is critically dependent on a TH2 cytokine response (controlled by cytokines IL-4, IL-5, IL-9, and IL-13). Recently, it has been shown that infecting mice with Toxoplasma gondii resulted in microbiota dysbiosis, ${ }^{[105]}$ characterized by a transient enrichment of Enterobacteriaceae belonging to Proteobacteria. The key observation in this study is that $T$. gondii-infected mice exhibited loss of Paneth cells in the small intestine via mitochondrial damage that was dependent on microbiota, TLR-11, IFN- $\gamma$, and MyD88 signaling in CD4+ T-cells. ${ }^{[105]}$ Interestingly,
T. gondii-induced microbiota dysbiosis is somewhat similar to the microbiotal alterations observed in animal models of intestinal inflammation and in human IBD, highlighting the opportunistic pathogenic activity of the Enterobacteriaceae family, specifically E. coli. Collectively, this study demonstrates that TLRs not only help preserve microbiotal homeostasis but also effect dysbiosis by damaging the host cells that normally secrete antimicrobial peptides.

\section{Diet and intestinal immunity}

Numerous studies have now demonstrated that diet plays a major role in the early development of the gut immune system directly and indirectly. Specifically, in addition to major macronutrients, micronutrients such as vitamins A and $\mathrm{D}$ and minerals such as iron can greatly influence the MIS. Recent additions to the list of increasingly notable dietary components are chemicals present in vegetables, specifically of the Brassicaceae family, as well as lactose in milk. Some dietary factors also promote disease pathogenesis, which include milk fat acting as a colitogenic factor in susceptible mice by favoring the growth of a specific bacterium, Bilophila wadsworthia. ${ }^{[106]}$

It has long been known that gluten-rich proteins (wheat, rye) are driving factors in the etiology of celiac disease (CD). Although the contribution of adaptive immunity in CD pathogenesis is well established, evidence on the direct involvement of innate immunity, which is required for 
linking adaptive immunity, is lacking. A recent study bridges this gap by demonstrating that the pest resistance molecules $[\alpha$-amylase/trypsin inhibitors (ATIs) CM3 and $0.19]$ in wheat act as strong activators of monocytes, macrophages, and DCs via TLR-4-MD2-CD14, thus initiating an immune response that results in the activation of adaptive immunity (T cells) that drives CD pathogenesis. ${ }^{[107]}$

\section{Conclusion}

In conclusion, the mammalian gut immune system should be viewed as a complex interplay between physical, chemical, and cellular barriers, a vast community of bacteria, and plethora of host immune cells which mediate innate and adaptive immunity. The intestinal microbiota helps in proper development of the host immune system, which in turn regulates the homeostasis of the microbiota. ${ }^{[108]}$ Accumulating evidence over the last decade indicates that the MIS and microbiota interaction should be finely balanced and any perturbations of this interaction would result in microbiotal and immune dysbiosis, leading to inflammatory disorders. The rapid surge in the emerging new-age disorders such as IBD, rheumatoid arthritis, cardiovascular disease, and metabolic syndrome has driven investigators to explore their etiology in multiple directions such as genetics, diet, and environmental factors, as well as MIS-microbiota interactions. In addition, the practice of strict hygienic and sanitary conditions and consumption of highly processed foods containing high fat, high carbohydrate, and low fiber with numerous food additives and preservatives may account for altered microbial composition, metabolism, and interaction with host immunity. Nearly all the above diseases are characterized by local as well as systemic low-grade chronic or sub-clinical inflammation in which the inflammation originated in the intestine via the interaction between host MIS and microbiota. Hippocrates (460-370 BC) stated, "All diseases begin in the gut."

\section{Acknowledgment}

BC is supported by Crohn's and Colitis Foundation of America (CCFA) Research Fellowship Award and M.V-K by NIH grants K01 (DK083275), R03 (094864), and R01 (DK097865).

\section{REFERENCES}

1. Oresic M, Seppanen-Laakso T, Yetukuri L, Backhed F, Hanninen V. Gut microbiota affects lens and retinal lipid composition. Exp Eye Res 2009;89:604-7.

2. Hamer HM, Jonkers D, Venema K, Vanhoutvin S, Troost FJ, Brummer RJ. Review article: The role of butyrate on colonic function. Aliment Pharmacol Ther 2008;27:104-19.
3. Kane M, Case LK, Kopaskie K, Kozlova A, MacDearmid C, Chervonsky AV, et al. Successful transmission of a retrovirus depends on the commensal microbiota. Science 2011;334:245-9.

4. Kuss SK, Best GT, Etheredge CA, Pruijssers AJ, Frierson JM, Hooper LV, et al. Intestinal microbiota promote enteric virus replication and systemic pathogenesis. Science 2011;334:249-52.

5. Chow J, Lee SM, Shen Y, Khosravi A, Mazmanian SK. Host-bacterial symbiosis in health and disease. Adv Immunol 2010;107:243-74.

6. O'Hara AM, Shanahan, F. The gut flora as a forgotten organ. EMBO Rep 2006;7:688-93.

7. Slack E, Hapfelmeier S, Stecher B, Velykoredko Y, Stoel M, Lawson MA, et al. Innate and adaptive immunity cooperate flexibly to maintain host-microbiota mutualism. Science 2009;325:617-20.

8. Hoshi H, Aijima H, Horie K, Nagata H, Kaneko T, Ikeda T. Lymph follicles and germinal centers in popliteal lymph nodes and other lymphoid tissues of germ-free and conventional rats. Tohoku J Exp Med 1992;166:297-307.

9. Turner JR. Intestinal mucosal barrier function in health and disease. Nat Rev Immunol 2009;9:799-809.

10. Johansson ME, Phillipson M, Petersson J, Velcich A, Holm L, Hansson GC. The inner of the two Muc2 mucin-dependent mucus layers in colon is devoid of bacteria. Proc Natl Acad Sci USA 2008;105:15064-9.

11. Johansson ME, Hansson GC. Mucus and the goblet cell. Dig Dis 2013;31:305-9.

12. Jass JR, Walsh MD. Altered mucin expression in the gastrointestinal tract: A review. J Cell Mol Med 2001;5:327-51.

13. Hasnain SZ, Gallagher AL, Grencis RK, Thornton DJ. A new role for mucins in immunity: Insights from gastrointestinal nematode infection. Int J Biochem Cell Biol 2013;45:364-74.

14. Shekels LL, Anway RE, Lin J, Kennedy MW, Garside P, Lawrence CE, et al. Coordinated Muc2 and Muc3 mucin gene expression in Trichinella spiralis infection in wild-type and cytokine-deficient mice. Dig Dis Sci 2001;46:1757-64.

15. Pillai K, Pourgholami MH, Chua TC, Morris DL. MUC1 as a potential target in anticancer therapies. Am J Clin Oncol 2013. doi: 10.1097/COC.0b013e31828f5a07.

16. Van der Sluis M, De Koning BA, De Bruijn AC, Velcich A, Meijerink JP, Van Goudoever JB, et al. Muc2-deficient mice spontaneously develop colitis, indicating that MUC2 is critical for colonic protection. Gastroenterology 2006;131:117-29.

17. McDole JR, Wheeler LW, McDonald KG, Wang B, Konjufca V, Knoop KA, et al. Goblet cells deliver luminal antigen to CD103+dendritic cells in the small intestine. Nature 2012;483:345-9.

18. Wei X, Yang Z, Rey FE, Ridaura VK, Davidson NO, Gordon JI, et al. Fatty acid synthase modulates intestinal barrier function through palmitoylation of mucin 2. Cell Host Microbe 2012;11:140-52.

19. Varedi M, Greeley GH, Jr, Herndon DN, Englander EW. A thermal injury-induced circulating factor (s) compromises intestinal cell morphology, proliferation, and migration. Am J Physiol 1999;277:G175-82.

20. Gordon JI, Schmidt GH, Roth KA. Studies of intestinal stem cells using normal, chimeric, and transgenic mice. FASEB J 1992;6:3039-50.

21. Mitic LL, Anderson JM. Molecular architecture of tight junctions. 
Annu Rev Physiol 1998;60:121-42.

22. Brant SR, Panhuysen CI, Nicolae D, Reddy DM, Bonen DK, Karaliukas R, et al. MDR1 Ala893 polymorphism is associated with inflammatory bowel disease. Am J Hum Genet 2003;73:1282-92.

23. Panwala CM, Jones JC, Viney JL. A novel model of inflammatory bowel disease: Mice deficient for the multiple drug resistance gene, mdr1a, spontaneously develop colitis. J Immunol 1998;161:5733-44.

24. Pott J, Hornef M. Innate immune signalling at the intestinal epithelium in homeostasis and disease. EMBO Rep 2012;13:684-98.

25. McCormick BA, Colgan SP, Delp-Archer C, Miller SI, Madara JL. Salmonella typhimurium attachment to human intestinal epithelial monolayers: Transcellular signalling to subepithelial neutrophils. J Cell Biol 1993;123:895-907.

26. Keates S, Keates AC, Mizoguchi E, Bhan A, Kelly CP. Enterocytes are the primary source of the chemokine ENA-78 in normal colon and ulcerative colitis. Am J Physiol 1997;273:G75-82.

27. Dwinell MB, Johanesen PA, Smith JM. Immunobiology of epithelial chemokines in the intestinal mucosa. Surgery 2003;133:601-7.

28. Gasperini S, Marchi M, Calzetti F, Laudanna C, Vicentini L, Olsen $\mathrm{H}$, et al. Gene expression and production of the monokine induced by IFN-gamma (MIG), IFN-inducible T cell alpha chemoattractant (I-TAC), and IFN-gamma-inducible protein-10 (IP-10) chemokines by human neutrophils. J Immunol 1999;162:4928-37.

29. Shibahara T, Wilcox JN, Couse T, Madara JL. Characterization of epithelial chemoattractants for human intestinal intraepithelial lymphocytes. Gastroenterology 2001;120:60-70.

30. Cromwell O, Hamid Q, Corrigan CJ, Barkans J, Meng Q, Collins PD, et al. Expression and generation of interleukin-8, IL-6 and granulocyte-macrophage colony-stimulating factor by bronchial epithelial cells and enhancement by IL-1 beta and tumour necrosis factor-alpha. Immunology 1992;77:330-7.

31. Sitaraman SV, Merlin D, Wang L, Wong M, Gewirtz AT, Si-Tahar M, et al. Neutrophil-epithelial crosstalk at the intestinal lumenal surface mediated by reciprocal secretion of adenosine and IL-6. J Clin Invest 2001;107:861-9.

32. Liu Y, Buhring HJ, Zen K, Burst SL, Schnell FJ, Williams IR, et al. Signal regulatory protein (SIRPalpha), a cellular ligand for CD47, regulates neutrophil transmigration. J Biol Chem 2002;277:10028-36.

33. Parkos CA, Colgan SP, Liang TW, Nusrat A, Bacarra AE, Carnes DK, et al. CD47 mediates post-adhesive events required for neutrophil migration across polarized intestinal epithelia. J Cell Biol 1996; $132: 437-50$

34. Colgan SP, Parkos CA, Delp C, Arnaout MA, Madara JL. Neutrophil migration across cultured intestinal epithelial monolayers is modulated by epithelial exposure to IFN-gamma in a highly polarized fashion. J Cell Biol 1993;120:785-98.

35. Aksentijevich I, Masters SL, Ferguson PJ, Dancey P, Frenkel J, van Royen-Kerkhoff $\mathrm{A}$, et al. An autoinflammatory disease with deficiency of the interleukin-1-receptor antagonist. N Engl J Med 2009;360:2426-37.

36. Arend WP, Malyak M, Guthridge CJ, Gabay C. Interleukin-1 receptor antagonist: Role in biology. Annu Rev Immunol 1998;16:27-55.

37. Molnarfi N, Hyka-Nouspikel N, Gruaz L, Dayer JM, Burger D. The production of IL-1 receptor antagonist in IFN-beta-stimulated human monocytes depends on the activation of phosphatidylinositol 3-kinase but not of STAT1. J Immunol 2005;174:2974-80.

38. Carvalho FA, Aitken JD, GewirtzAT, Vijay-Kumar M. TLR5 activation induces secretory interleukin-1 receptor antagonist (sIL-1Ra) and reduces inflammasome-associated tissue damage. Mucosal Immunol 2011;4:102-11.

39. Kiyono H, Fukuyama S. NALT- versus Peyer's-patch-mediated mucosal immunity. Nat Rev Immunol 2004;4:699-710.

40. Kraehenbuhl JP, Neutra MR. Epithelial M cells: Differentiation and function. Annu Rev Cell Dev Biol 2000;16:301-32.

41. Jepson MA, Clark MA, Hirst BH. M cell targeting by lectins: A strategy for mucosal vaccination and drug delivery. Adv Drug Deliv Rev 2004;56:511-25.

42. Pickard JM, Chervonsky AV. Sampling of the intestinal microbiota by epithelial M cells. Curr Gastroenterol Rep 2010;12:331-9.

43. Baumler AJ, Tsolis RM, Heffron F. The lpf fimbrial operon mediates adhesion of Salmonella typhimurium to murine Peyer's patches. Proc Natl Acad Sci USA 1996;93:279-83.

44. Chassaing B, Rolhion N, de Vallee A, Salim SY, Prorok-Hamon M, Neut C, et al. Crohn disease--associated adherent-invasive E. coli bacteria target mouse and human Peyer's patches via long polar fimbriae. J Clin Invest 2011;121:966-75.

45. Jang MH, Kweon MN, Iwatani K, Yamamoto M, Terahara K, Sasakawa C, et al. Intestinal villous M cells: An antigen entry site in the mucosal epithelium. Proc Natl Acad Sci USA 2004;101:6110-5.

46. Gallo RL, Hooper LV. Epithelial antimicrobial defence of the skin and intestine. Nat Rev Immunol 2012;12:503-16.

47. Clevers HC, Bevins CL. Paneth cells: Maestros of the small intestinal crypts. Annu Rev Physiol 2013;75:289-311.

48. Ghosh D, Porter E, Shen B, Lee SK, Wilk D, Drazba J, et al. Paneth cell trypsin is the processing enzyme for human defensin-5. Nat Immunol 2002;3:583-90.

49. Putsep K, Axelsson LG, Boman A, Midtvedt T, Normark S Boman HG, et al. Germ-free and colonized mice generate the same products from enteric prodefensins. J Biol Chem 2000;275:40478-82.

50. Ayabe T, Satchell DP, Wilson CL, Parks WC, Selsted ME, Ouellette AJ. Secretion of microbicidal alpha-defensins by intestinal Paneth cells in response to bacteria. Nat Immunol 2000;1:113-8.

51. Smythies LE, Sellers M, Clements RH, Mosteller-Barnum M, Meng G, Benjamin WH, et al. Human intestinal macrophages display profound inflammatory anergy despite avid phagocytic and bacteriocidal activity. J Clin Invest 2005;115:66-75.

52. Mowat AM, Bain CC. Mucosal macrophages in intestinal homeostasis and inflammation. J Innate Immun 2011;3:550-64.

53. Murai M, Turovskaya O, Kim G, Madan R, Karp CL, Cheroutre H, et al. Interleukin 10 acts on regulatory $\mathrm{T}$ cells to maintain expression of the transcription factor Foxp3 and suppressive function in mice with colitis. Nat Immunol 2009;10:1178-84.

54. Rugtveit J, Bakka A, Brandtzaeg P. Differential distribution of B7.1 (CD80) and B7.2 (CD86) costimulatory molecules on mucosal macrophage subsets in human inflammatory bowel disease (IBD). Clin Exp Immunol 1997;110:104-13.

55. Qualls JE, Kaplan AM, van Rooijen N, Cohen DA. Suppression of experimental colitis by intestinal mononuclear phagocytes. J Leukoc Biol 2006;80:802-15. 
56. MacDonald KP, Palmer JS, Cronau S, Seppanen E, Olver S, Raffelt NC, et al. An antibody against the colony-stimulating factor 1 receptor depletes the resident subset of monocytes and tissue- and tumor-associated macrophages but does not inhibit inflammation. Blood 2010;116:3955-63.

57. Hontecillas R, Horne WT, Climent M, Guri AJ, Evans C, Zhang Y, et al. Immunoregulatory mechanisms of macrophage PPAR-gamma in mice with experimental inflammatory bowel disease. Mucosal Immunol 2011;4:304-13.

58. Kuhn R, Lohler J, Rennick D, Rajewsky K, Muller W. Interleukin-10-deficient mice develop chronic enterocolitis. Cell $1993 ; 75: 263-74$.

59. Takeda K, Clausen BE, Kaisho T, Tsujimura T, Terada N, Forster I, et al. Enhanced Th1 activity and development of chronic enterocolitis in mice devoid of Stat3 in macrophages and neutrophils. Immunity 1999; 10:39-49.

60. Ivanov II, Frutos Rde L, Manel N, Yoshinaga K, Rifkin DB, Sartor RB, et al. Specific microbiota direct the differentiation of IL-17-producing T-helper cells in the mucosa of the small intestine. Cell Host Microbe 2008;4:337-49.

61. Strauch UG, Obermeier F, Grunwald N, Gurster S, Dunger N, Schultz M, et al. Influence of intestinal bacteria on induction of regulatory $\mathrm{T}$ cells: Lessons from a transfer model of colitis. Gut 2005;54:1546-52.

62. Brand S. Crohn's disease: Th1, Th17 or both? The change of a paradigm: new immunological and genetic insights implicate Th17 cells in the pathogenesis of Crohn's disease. Gut 2009;58:1152-67.

63. Aggarwal S, Ghilardi N, Xie MH, de Sauvage FJ, Gurney AL. Interleukin-23 promotes a distinct $\mathrm{CD} 4 \mathrm{~T}$ cell activation state characterized by the production of interleukin-17. J Biol Chem 2003;278:1910-4.

64. Bettelli E, Carrier Y, Gao W, Korn T, Strom TB, Oukka M, et al. Reciprocal developmental pathways for the generation of pathogenic effector TH17 and regulatory T cells. Nature 2006;441:235-8.

65. Mangan PR, Harrington LE, O'Quinn DB, Helms WS, Bullard DC, Elson CO, et al. Transforming growth factor-beta induces development of the T (H) 17 lineage. Nature 2006;441:231-4.

66. Coombes JL, Powrie F. Dendritic cells in intestinal immune regulation. Nat Rev Immunol 2008;8:435-46.

67. Lelouard H, Fallet M, de Bovis B, Meresse S, Gorvel JP. Peyer's patch dendritic cells sample antigens by extending dendrites through $\mathrm{M}$ cell-specific transcellular pores. Gastroenterology 2012;142:592-601. e3.

68. Rescigno M, Urbano M, Valzasina B, Francolini M, Rotta G, Bonasio R, et al. Dendritic cells express tight junction proteins and penetrate gut epithelial monolayers to sample bacteria. Nat Immunol 2001;2:361-7.

69. Coombes JL, Siddiqui KR, Arancibia-Carcamo CV, Hall J, Sun CM, Belkaid $\mathrm{Y}$, et al. A functionally specialized population of mucosal CD103+DCs induces Foxp3+regulatory T cells via a TGF-beta and retinoic acid-dependent mechanism. J Exp Med 2007;204:1757-64.

70. Walker JA, Barlow JL, McKenzie AN. Innate lymphoid cells-how did we miss them? Nat Rev Immunol 2013;13:75-87.

71. Pearson T, Shultz LD, Miller D, King M, Laning J, Fodor W, et al. Non-obese diabetic-recombination activating gene-1 (NOD-Rag1 null) interleukin (IL)-2 receptor common gamma chain (IL2r gamma null) null mice: A radioresistant model for human lymphohaematopoietic engraftment. Clin Exp Immunol 2008;154:270-84.

72. Tait Wojno ED, Artis D. Innate lymphoid cells: Balancing immunity, inflammation, and tissue repair in the intestine. Cell Host Microbe $2012 ; 12: 445-57$

73. Sonnenberg GF, Monticelli LA, Alenghat T, Fung TC, Hutnick NA, Kunisawa $\mathrm{J}$, et al. Innate lymphoid cells promote anatomical containment of lymphoid-resident commensal bacteria. Science 2012;336:1321-5.

74. Hooper LV, Macpherson AJ. Immune adaptations that maintain homeostasis with the intestinal microbiota. Nat Rev Immunol 2010;10:159-69.

75. Pabst $\mathrm{O}$. New concepts in the generation and functions of IgA. Nat Rev Immunol 2012;12:821-32.

76. Fukata M, Shang L, Santaolalla R, Sotolongo J, Pastorini C, Espana C, et al. Constitutive activation of epithelial TLR4 augments inflammatory responses to mucosal injury and drives colitis-associated tumorigenesis. Inflamm Bowel Dis 2011;17:1464-73.

77. Geuking MB, Cahenzli J, Lawson MA, Ng DC, Slack E, Hapfelmeier $\mathrm{S}$, et al. Intestinal bacterial colonization induces mutualistic regulatory T cell responses. Immunity 2011;34:794-806.

78. Clark JA, Callicoat PA, Brenner NA, Bradley CA, Smith DM Jr. Selective IgA deficiency in blood donors. Am J Clin Pathol 1983;80:210-3.

79. Mbawuike IN, Pacheco S, Acuna CL, Switzer KC, Zhang Y, Harriman GR. Mucosal immunity to influenza without IgA: An IgA knockout mouse model. J Immunol 1999;162:2530-7.

80. Hooper LV, Midtvedt T, Gordon JI. How host-microbial interactions shape the nutrient environment of the mammalian intestine. Annu Rev Nutr 2002;22:283-307.

81. Koren O, Spor A, Felin J, Fak F, Stombaugh J, Tremaroli V, et al. Human oral, gut, and plaque microbiota in patients with atherosclerosis. Proc Natl Acad Sci USA 2011;108 Suppl 1:4592-8.

82. Koren O, Goodrich JK, Cullender TC, Spor A, Laitinen K, Backhed HK, et al. Host remodeling of the gut microbiome and metabolic changes during pregnancy. Cell 2012;150:470-80.

83. Wostmann BS, Larkin C, Moriarty A, Bruckner-Kardoss E. Dietary intake, energy metabolism, and excretory losses of adult male germfree Wistar rats. Lab Anim Sci 1983;33:46-50.

84. Chassaing B, Aitken JD, Gewirtz AT, Vijay-Kumar M. Gut microbiota drives metabolic disease in immunologically altered mice. Adv Immunol 2012;116:93-112.

85. Carvalho FA, Aitken JD, Vijay-Kumar M, Gewirtz AT. Toll-like receptor-gut microbiota interactions: Perturb at your own risk! Annu Rev Physiol 2012;74:177-98.

86. Vamadevan AS, Fukata M, Arnold ET, Thomas LS, Hsu D, Abreu MT. Regulation of Toll-like receptor 4-associated MD-2 in intestinal epithelial cells: A comprehensive analysis. Innate Immun 2010;16:93-103.

87. Furrie E, Macfarlane S, Thomson G, Macfarlane GT. Toll-like receptors-2, -3 and -4 expression patterns on human colon and their regulation by mucosal-associated bacteria. Immunology 2005;115:565-74.

88. Gewirtz AT, Navas TA, Lyons S, Godowski PJ, Madara JL. Cutting edge: Bacterial flagellin activates basolaterally expressed TLR5 to induce epithelial proinflammatory gene expression. J Immunol 2001;167:1882-5. 
89. Ghadimi D, Vrese M, Heller KJ. Schrezenmeir, J. Effect of natural commensal-origin DNA on toll-like receptor 9 (TLR9) signaling cascade, chemokine IL-8 expression, and barrier integritiy of polarized intestinal epithelial cells. Inflamm Bowel Dis 2010;16:410-27.

90. Vilaysane A, Muruve DA. The innate immune response to DNA. Semin Immunol 2009;21:208-14.

91. Biswas SK, Lopez-Collazo E. Endotoxin tolerance: New mechanisms, molecules and clinical significance. Trends Immunol 2009;30:475-87.

92. Elinav E, Thaiss CA, Flavell RA. Analysis of microbiota alterations in inflammasome-deficient mice. Methods Mol Biol 2013;1040:185-94.

93. Henao-Mejia J, Elinav E, Jin C, Hao L, Mehal WZ, Strowig T, et al. Inflammasome-mediated dysbiosis regulates progression of NAFLD and obesity. Nature 2012;482:179-85.

94. Nunes T, de Souza HS. Inflammasome in intestinal inflammation and cancer. Mediators Inflamm 2013;2013:654963.

95. Nenci A, Becker C, Wullaert A, Gareus R, van Loo G, Danese S, et al. Epithelial NEMO links innate immunity to chronic intestinal inflammation. Nature 2007;446:557-61.

96. Rakoff-Nahoum S, Paglino J, Eslami-Varzaneh F, Edberg S, Medzhitov R. Recognition of commensal microflora by toll-like receptors is required for intestinal homeostasis. Cell 2004;118:229-41.

97. Jones RM, Sloane VM, Wu H, Luo L, Kumar A, Kumar MV, et al. Flagellin administration protects gut mucosal tissue from irradiation-induced apoptosis via MKP-7 activity. Gut 2011;60:648-57.

98. Powell N, Walker AW, Stolarczyk E, Canavan JB, Gokmen MR, Marks E, et al. The transcription factor T-bet regulates intestinal inflammation mediated by interleukin-7 receptor+innate lymphoid cells. Immunity 2012;37:674-84.

99. Garrett WS, Lord GM, Punit S, Lugo-Villarino G, Mazmanian SK,
Ito $\mathrm{S}$, et al. Communicable ulcerative colitis induced by T-bet deficiency in the innate immune system. Cell 2007;131:33-45.

100. Neufert C, Pickert G, Zheng Y, Wittkopf N, Warntjen M, Nikolaev A, et al. Activation of epithelial STAT3 regulates intestinal homeostasis. Cell Cycle 2010;9:652-5.

101. Pickert G, Neufert C, Leppkes M, Zheng Y, Wittkopf N, Warntjen M, et al. STAT3 links IL-22 signaling in intestinal epithelial cells to mucosal wound healing. J Exp Med 2009;206:1465-72.

102. Smith PM, Howitt MR, Panikov N, Michaud M, Gallini CA, Bohlooly YM, et al. The microbial metabolites, short-chain fatty acids, regulate colonic Treg cell homeostasis. Science 2013;341:569-73.

103. Arpaia N, Campbell C, Fan X, Dikiy S, van der Veeken J, Deroos P, et al. Metabolites produced by commensal bacteria promote peripheral regulatory T-cell generation. Nature 2013;504:451-5.

104. Marcos LA, Gotuzzo E. Intestinal protozoan infections in the immunocompromised host. Curr Opin Infect Dis 2013;26:295-301.

105. Raetz M, Hwang SH, Wilhelm CL, Kirkland D, Benson A, Sturge CR, et al. Parasite-induced TH1 cells and intestinal dysbiosis cooperate in IFN-gamma-dependent elimination of Paneth cells. Nat Immunol $2013 ; 14: 136-42$

106. Devkota S, Wang Y, Musch MW, Leone V, Fehlner-Peach H, Nadimpalli A, et al. Dietary-fat-induced taurocholic acid promotes pathobiont expansion and colitis in Il10-/- mice. Nature 2012;487:104-8.

107. Junker Y, Zeissig S, Kim SJ, Barisani D, Wieser H, Leffler DA, et al. Wheat amylase trypsin inhibitors drive intestinal inflammation via activation of toll-like receptor 4. J Exp Med 2012;209:2395-408.

108. Sommer F, Backhed F. The gut microbiota-masters of host development and physiology. Nat Rev Microbiol 2013;11:227-38. 